\title{
Informações de custos e qualidade do gasto público: lições da experiência internacional*
}

\author{
Fernando Rezende** \\ Armando Cunha*** \\ Roberto Bevilacqua****
}

\begin{abstract}
SumÁRio: 1. Introdução; 2 . A importância de informações sobre custos para a melhoria da qualidade do gasto público; 3. Motivações e objetivos para a adoção de regimes contábeis que gerem informações sobre os custos do governo; 4. A adoção da contabilidade de competência deve levar necessariamente à adoção também de um orçamento de competência?; 5. O debate atual: da informação à decisão; 6. A experiência internacional e as diretrizes para adoção de um sistema de custos no setor público brasileiro; 7. Síntese e conclusões.
\end{abstract}

Summary: 1 . Introduction; 2 . The importance of cost information for the improvement of public expenditure; 3 . Motives and goals of accounting regimes that manage government expenditure information; 4 . The adoption of accrual accounting must necessarily also lead to accrual budgeting?; 5 . The current debate: from information to decision; 6. International experience and the guidelines for the adoption of a costing system in the Brazilian public sector; 7. Summary and conclusions.

\footnotetext{
* Artigo recebido em fev. e aceito em maio 2010.

** Professor de finanças públicas e política fiscal e coordenador do Programa de Estudos Fiscais da Escola Brasileira de Administração Pública e de Empresas da FGV (Ebape/FGV). Ex-presidente do Ipea (1996-98) e consultor de organizações internacionais (BID, Banco Mundial e ONU). Foi assessor especial no Ministério do Desenvolvimento, Indústria e Comércio Exterior. Autor de vários trabalhos publicados no país e no exterior. Endereço: Praia de Botafogo 190, 5o andar - CEP 22250-900, Rio de Janeiro, RJ, Brasil. E-mail: fernando.rezende@fgv.br.

$* * *$ Professor do quadro e ex-diretor da Ebape/FGV (1992-99). Pesquisador do Programa de Estudos Fiscais. Coordenador do Curso de Pós-Graduação em Administração Pública (Cipad) e membro do comitê editorial do International Public Management Journal. Endereço: Praia de Botafogo, 190, 5o andar - CEP 22250-900, Rio de Janeiro, RJ, Brasil. E-mail: armando.cunha@fgv.br.

***** Mestre em administração pública e bacharel em administração pela Ebape/FGV. Professor nos programas de educação executiva e consultor da FGV. Exerceu funções de direção e assessoramento em organizações do governo federal nas áreas da cultura e da assistência social. Endereço: Praia de Botafogo, 190, 6o andar - CEP 22250-900, Rio de Janeiro, RJ, Brasil. E-mail: roberto.otero@fgv.br.
} 
Palavras-chave: custos; governo; gasto público; orçamento.

KEY WORDs: costs; government; public expenditure; budget.

O conhecimento dos custos do governo é de suma importância para a adoção de mudanças nos procedimentos que regem as decisões sobre o uso dos recursos públicos, bem como sobre os métodos aplicados à gestão das políticas e dos programas governamentais, de modo a aumentar o valor dos recursos aplicados pelo governo e ampliar o benefício social da tributação. Sob a ótica dos especialistas em orçamento, a questão está em escolher a melhor maneira de usar as informações geradas pela contabilidade de competência para aumentar a eficiência e melhorar a qualidade do gasto. Uns defendem que tais informações devem ser vistas como mais uma ferramenta importante para a melhoria das decisões sobre o uso dos recursos públicos. Outros, que elas poderiam revolucionar o processo orçamentário levando à posterior adoção do orçamento de competência. Este artigo explora essa questão, com base na análise de experiências internacionais, apontando para aspectos relevantes que devem ser observados na sequência dos debates sobre esse tema no Brasil.

Government cost information and the quality of public expenditure: lessons from the international experience

Allocation and management of public funds can be significantly improved when good information on costs of producing and delivering public goods and services is regularly available, so that tax payers' money can bring better social benefits. Pundits diverge on which is the best way to use the information on government costs extracted from the adoption of accrual accounting in the public sector. Some argue in favor of using such information as an important tool for improving decision making during the regular budgetary process. Others support the idea of revolutionizing the whole budget by adopting the so-called accrual budgeting. This article explores this question on the basis of evidences provided by international experiences and points to important elements that should be taken into account in the ongoing debate in Brazil.

\section{Introdução}

Nas duas últimas décadas, importantes mudanças nos métodos adotados para aferir os custos das ações públicas foram adotadas, em vários países, como uma reação às exigências de preservação da responsabilidade fiscal e às pressões da sociedade por transparência das decisões sobre a utilização dos recursos orçamentários e melhoria da qualidade dos bens e serviços postos à disposição das respectivas populações.

Tais mudanças se voltaram para a adoção pelo setor público de sistemas contábeis afins aos praticados pela iniciativa privada, tendo em vista que a 
contabilidade orçamentária tradicional não gera informações adequadas para que se conheça o real custo dos bens e serviços produzidos por organizações governamentais. Em decorrência, não permite que os custos incorridos sejam comparados aos resultados obtidos e que seja possível avaliar a eficiência das ações governamentais para analisar alternativas que poderiam obter idênticos resultados com custos menores.

Em boa parte dos casos, a mudança no regime contábil foi parte de um processo de reformas abrangentes nos processos orçamentários, que se originaram de pressões para promover o ajuste das contas públicas. Tudo em um contexto de limitações impostas pela abertura econômica e a globalização dos mercados ao recurso a aumento de impostos para corrigir o desequilíbrio fiscal. Assim, para evitar prejuízos que aumentos na carga tributária provocam, com respeito à competitividade econômica, a contenção do crescimento dos gastos, apoiada em melhor conhecimento sobre onde economizar sem comprometer a provisão de serviços essenciais, ganhou destaque nas providências adotadas para promover o ajuste fiscal.

Tal esforço contrasta com a opção brasileira de promover o ajuste fiscal mediante sucessivos aumentos da carga tributária, tendo em vista as dificuldades para conter a expansão dos gastos e a inexistência de informações que permitissem identificar ineficiências e desperdícios, para que a redução dos gastos não comprometesse programas e ações indispensáveis à melhoria das condições sociais e ao desenvolvimento do país.

O esgotamento das possibilidades de continuar sustentando o ajuste fiscal mediante aumento de impostos requer agora maior atenção aos gastos. Para isso, é necessário desenvolver um sistema de informações que permita avaliar os custos dos programas e atividades mantidos pelo governo, de modo a evitar o tradicional recurso a cortes lineares que prejudicam atividades essenciais sem afetar aquelas que são exercidas com um nível elevado de ineficiência. Assim, cabe examinar em que medida as principais experiências internacionais de adoção de métodos contábeis para aferir os custos governamentais oferecem lições importantes para as mudanças necessárias no caso brasileiro.

Entre os países selecionados para fins da apreciação dessas experiências, à luz dos interesses específicos do Brasil, estão incluídos os pioneiros, como a Austrália, a Nova Zelândia e o Reino Unido, que adotaram o regime de competência no bojo de reformas abrangentes em todo o processo orçamentário. Outros que implantaram a contabilidade de competência e evoluíram posteriormente para estender esse regime ao processo orçamentário, como a Dinamarca e a Suíça, e outros, ainda, que são exemplos de reformas moder- 
nizadoras, mas que optaram por não estender o regime de competência ao orçamento, como a Suécia e a Holanda. Completam a lista os Estados Unidos e o Canadá, que também implantaram a contabilidade de competência no setor público sem estender esse regime a todo o orçamento. Os traços marcantes das experiências desse conjunto de países, de características bem distintas, oferecem um interessante painel para orientar a elaboração e condução de um processo que visa agregar informações relevantes para a adoção de iniciativas voltadas para a melhoria da eficiência e da eficácia do Estado brasileiro.

\section{A importância de informações sobre custos para a melhoria da qualidade do gasto público}

A preocupação com a geração de informações sobre o real custo das atividades exercidas pelo governo ganhou força no bojo das demandas por melhoria da performance e da eficiência do setor público, e da concomitante pressão por mudanças na contabilidade pública, para que decisões sobre o uso dos recursos orçamentários tenham por foco os resultados a ser obtidos com os recursos extraídos da população por meio dos impostos. Assim, não basta saber quanto o governo gasta com a provisão de bens e serviços, é importante saber qual o resultado gerado por esse gasto e se esse mesmo resultado poderia ser alcançado com menores custos para o contribuinte.

Como as informações geradas pela contabilidade usualmente adotada no setor público privilegiam os fluxos de caixa, não fornecendo as informações necessárias para aferir os custos, a ênfase na qualidade do gasto teve que ser acompanhada da introdução de mudanças contábeis que atendessem a essa necessidade. Para medir os custos, é preciso conhecer os recursos efetivamente consumidos na provisão de um determinado bem ou serviço, em um dado período, assim como a decorrente variação do ativo e do passivo governamental ocorrida no mesmo período, informações geradas pela contabilidade de competência (accrual accounting) adotada no setor privado. A diferença em relação à contabilidade de caixa é que esta última registra os valores financeiros no período em que os fatos que geram receitas e despesas ocorrem e as obrigações são assumidas e não naquele em que os desembolsos são efetivados.

As principais diferenças nos resultados fiscais obtidos mediante um regime de caixa e um regime de competência se devem ao tempo em que as informações são registradas, e são verificadas com maior intensidade na apropriação de receitas, na aquisição de ativos e nas despesas com juros e benefícios previdenciários de servidores públicos. Como a contabilidade de competência mede 
o efetivo consumo de recursos, sua aplicação gera resultados distintos para as atividades que são mais intensivas em capital e que demandam um grande volume de recursos materiais para serem exercidas. Nesses casos, pelo regime de competência, os custos são apurados com base no capital efetivamente consumido no ano, isto é, o valor de sua depreciação, e nos materiais utilizados na produção dos serviços, o que é medido pela variação dos respectivos estoques.

Na área de transportes, por exemplo, o custo anual de um programa de conservação de rodovias seria medido pela depreciação das máquinas e demais equipamentos utilizados nessa conservação e não nas despesas de investimento ocorridas no mesmo período. De outra parte, o custo da provisão de serviços médicos computaria a variação dos estoques de medicamentos e outros materiais utilizados, e não o total das despesas anuais com sua aquisição.

Outra preocupação importante que a aplicação da contabilidade de competência procura atender tem a ver com a avaliação das implicações de longo prazo de decisões adotadas no presente, cuja não consideração pode gerar riscos fiscais que irão comprometer a solvência do setor público anos à frente. Nesse particular, as áreas de pessoal e de previdência social estão entre as que podem se beneficiar da adoção desse regime contábil, pois os compromissos futuros com benefícios previdenciários e programas de seguro social passam a ser registrados no momento em que as obrigações são assumidas, gerando informações importantes para balizar decisões políticas que impliquem mudanças com impactos negligenciáveis no curto prazo, mas com potencial de comprometer a sustentabilidade fiscal.

Quando comparado ao método baseado no regime de caixa para medir os resultados fiscais, a contabilidade de competência apresentaria a vantagem de ser menos vulnerável a procedimentos que podem gerar resultados mais favoráveis, a exemplo da venda de patrimônio público (privatização), da antecipação de receitas tributárias e da postergação de pagamentos. No entanto, conforme assinala Schick (2007), em um regime de competência os resultados dependem de premissas adotadas com respeito a taxas de juros e de desconto, bem como da reavaliação de ativos, cuja mudança também pode alterar os resultados. Uma importante diferença, que é destacada para justificar a adoção de um regime de competência no setor público, é a transparência das regras que regulam a contabilidade de organizações privadas, além da existência de organismos independentes encarregados de auditar os números publicados.

Convém ressaltar, entretanto, que em nenhum dos casos em que a contabilidade de competência foi adotada para informar decisões orçamentárias, a geração de informações sobre os fluxos de receita e despesa foi abandonada, pois ela é mais fácil de ser compreendida pelo grande público, é necessária para 
fornecer informações sobre o total de investimentos a ser realizado em um determinado período, e produz melhores indicadores na situação fiscal do governo no curto prazo. Essas e outras razões fazem com que seja necessário operar os dois registros contábeis simultaneamente, mediante procedimentos que permitam extrair as informações requeridas para atender a diferentes propósitos.

\section{Quadro 1 \\ Por que é importante adotar um sistema de informações sobre custos na administração pública}

- Há várias razões para a adoção de procedimentos que permitam aferir os custos do governo, mas a mais importante delas é que sem que se conheçam os custos das políticas e programas executados pelo setor público é impossível saber se o dinheiro do contribuinte está sendo bem utilizado.

- Para saber se os recursos oriundos do pagamento de impostos estão sendo bem utilizados é necessário comparar os custos com os resultados para responder às seguintes perguntas: um dado resultado (por exemplo, a melhoria no desempenho escolar) está sendo obtido ao menor custo possível, ou existe um grande desperdício? Alternativamente, com os mesmos recursos aplicados seria possível conseguir resultados melhores?

- Portanto, o conhecimento dos custos é indispensável para que o governo tome providências para meIhorar a qualidade do gasto público e para que a população se mobilize para pressioná-lo a tomar as providências necessárias. Melhorando a qualidade do gasto e reduzindo desperdícios é possível baixar os impostos sem comprometer os serviços essenciais e os programas sociais.

- Isso chama atenção para outra razão importante para a adoção de um sistema que gere informações sobre os custos do governo: a transparência do gasto público e a possibilidade de um melhor controle democrático sobre as prioridades no uso dos recursos públicos e a qualidade dos serviços prestados.

- O conhecimento dos custos é também importante para evitar o descontrole das finanças públicas e o recurso a aumento de impostos para cobrir decisões irresponsáveis e desperdícios. Decisões de investimento, por exemplo, geram gastos futuros com o custeio dos serviços e a manutenção de equipamentos que, se não forem devidamente considerados, provocarão desequilíbrios.

- Apesar da sua importância, o governo brasileiro não dispõe atualmente dessa informação. Por se concentrar nos fluxos de caixa, as informações atualmente geradas pela contabilidade pública indicam quanto foi gasto em um determinado programa em um dado período, por exemplo, um ano, mas não o seu real custo. Para aferir o custo é necessário saber, por exemplo, o valor dos materiais empregados na prestação dos serviços (medicamentos e outros no caso da saúde), a depreciação de equipamentos e instalações, o custo do pessoal empregado, inclusive os encargos previdenciários, e demais gastos com o funcionamento do órgão encarregado de prover os serviços, como energia e comunicações.

- Para gerar as informações que permitem aferir os custos do governo é preciso que o setor público adote a contabilidade de competência utilizada no setor privado. Por esse regime, as informações financeiras são apropriadas quando o fato ocorre e não quando o desembolso é efetivado. Por exemplo, na apuração dos custos dos serviços de saúde em um dado ano, a parcela relativa a medicamentos inclui o valor de medicamentos adquiridos no ano anterior e consumidos no ano corrente, mais a parcela de medicamentos adquiridos e consumidos no mesmo ano, valor que obviamente difere das despesas realizadas com a aquisição de medicamentos no ano corrente. 
Sem a adoção da contabilidade de competência, no entanto, é impossível avançar na implementação de uma reforma na gestão pública que tenha por foco aumentar o valor dos recursos aplicados pelo governo e, portanto, ampliar o benefício social da tributação. Por isso, ela constitui um passo essencial com vistas à realização de mudanças que recuperem a importância e a qualidade do orçamento enquanto instrumento de decisões sobre o uso alternativo de recursos fiscais, tendo em vista a adoção de escolhas que maximizem seus ganhos para a sociedade brasileira.

\section{Motivações e objetivos para a adoção de regimes contábeis que gerem informações sobre os custos do governo}

Nos países que avançaram na adoção da contabilidade de competência pelo setor público, as motivações diferem com respeito ao uso a ser dado às informações geradas por esse regime. Em alguns casos, a adoção da contabilidade de competência foi parte de uma reforma abrangente na administração pública, voltada para promover a eficiência das organizações governamentais, mediante a utilização de métodos de gestão semelhantes aos adotados por organizações privadas.

Nessa reforma, a adoção da contabilidade de competência seria uma etapa indispensável à posterior adoção do orçamento de competência. Em outros casos, a adoção da contabilidade de competência é vista como uma providência necessária para gerar informações que contribuam para melhorar a qualidade de gasto e avaliar os riscos fiscais, mas a alocação de recursos orçamentários se mantém no regime de caixa.

A contabilidade de competência não se confunde, portanto, com a proposta do orçamento de competência, que advoga mudanças profundas na forma como os recursos orçamentários são alocados e nos controles sobre a liberação dos fluxos financeiros. O quadro 2 destaca as principais diferenças entre essas duas situações.

Nos países que optaram por adotar o orçamento de competência, além das pressões para conter a expansão dos gastos e controlar seu crescimento, essa opção buscou também estabelecer um novo relacionamento entre os po- 


\section{Quadro 2}

\section{Contabilidade de competência e orçamento de competência — diferenças}

\section{Contabilidade de competência}

- A contabilidade de competência é um regime contábil abrangente, que tem por finalidade fornecer informações detalhadas sobre as transações realizadas por organizações públicas ou privadas, tendo em vista a aferição do desempenho e da saúde financeira dessas organizações. Para tanto, ela registra não apenas os fluxos de entrada e saída de recursos no caixa, mas também as operações que implicam variação do seu patrimônio.

- Na contabilidade de competência, as informações são registradas no período em que os fatos que geram receitas e despesas ocorrem e em que obrigações são assumidas e não no momento em que os desembolsos ocorrem.

- A contabilidade de competência é universalmente adotada no setor privado e obedece a padrões internacionais que visam uniformizar os procedimentos e permitir a comparação do desempenho de empresas que atuam no mercado global. A uniformidade, a transparência e a confiabilidade das normas contábeis aplicadas ao setor empresarial são importantes para a ação dos órgãos reguladores, bem como para acionistas e consumidores interessados em investir nessas empresas ou em consumir seus produtos.

- A adoção da contabilidade de competência no setor público é um fenômeno recente, impulsionado pelas reformas voltadas para a modernização da gestão pública, com foco no resultado nas ações governamentais, e pela demanda de agências de avaliação de risco de informações comparáveis e confiáveis sobre a saúde financeira dos governos em face da globalização do mercado financeiro. Um dos países pioneiros na adoção da contabilidade de competência no setor público - a Suécia - implantou esse regime no início da década de 1980.

- Como um regime contábil que permite aferir o custo de políticas e programas governamentais, a contabilidade de competência pode ser um importante complemento às informações geradas pelo regime de caixa e uma ferramenta de grande utilidade para aperfeiçoar as decisões sobre a alocação dos recursos públicos, através do conhecimento de como os custos se relacionam com os respectivos resultados. Alternativamente, as informações geradas pela contabilidade de competência podem passar a ser a referência para a elaboração e a execução do orçamento público, caso em que estaríamos falando de um orçamento de competência.

\section{Orçamento de competência}

- A adoção da contabilidade de competência é precondição para a implantação do orçamento de competência, mas essa não é a principal finalidade de sua adoção. As informações geradas pela contabilidade de competência são de grande utilidade para acrescentar elementos que ajudam a melhorar as decisões orçamentárias sem que seja necessário, ou até mesmo desejável, evoluir na direção do orçamento de competência.

- Os poucos países que avançaram na direção do orçamento de competência o fizeram movidos por propósitos mais amplos de reforma na gestão pública, que tinha como objetivo buscar maior eficiência no uso dos recursos públicos mediante a introdução de competição na provisão de serviços públicos, tanto no âmbito das organizações governamentais quanto por meio da provisão de idênticos serviços por organizações privadas. 
- A contabilidade de competência é precondição para o orçamento de competência, porque os custos passam a ser a referência para as decisões de alocação de recursos do orçamento. Uma vez tomada a decisão de evoluir na direção do orçamento de competência, é feita uma rigorosa análise dos recursos materiais, humanos e financeiros com que cada órgão do governo conta para dar conta de suas responsabilidades - o chamado balanço inicial. Constatados desequilíbrios (excesso ou escassez), ajustes devem ser feitos para evitar problemas futuros. A partir daí, o orçamento é repartido de modo a garantir que os recursos de cada organização se mantenham nos níveis necessários para o exercício de suas responsabilidades. Da qualidade do balanço inicial depende, portanto, o resultado da mudança no regime orçamentário.

- Na sua forma pura, após o orçamento apresentado pelos órgãos setoriais ser aprovado pelo Legislativo, os recursos ficam automaticamente à sua disposição, não havendo controles sobre a liberação dos fluxos financeiros dentro dos limites aprovados.

- Uma das principais mudanças introduzidas pelo orçamento de competência se refere ao tratamento dispensado aos investimentos. Adotado esse modelo, as verbas atribuídas a cada órgão da administração pública incluem o valor da depreciação dos respectivos ativos, ficando os dirigentes desses órgãos com a responsabilidade de administrar esses recursos e promover a reposição da parcela depreciada. Apenas os novos investimentos necessários para projetos de expansão e modernização são negociados.

- No orçamento de competência, as organizações públicas setoriais passam a gozar de total autonomia para gerir os recursos orçamentários a elas atribuídos, ficando responsável por cumprir metas de resultados estabelecidas e sujeitas a pressões dos usuários dos serviços e a penalidades na falta de justificativas para o não cumprimento.

deres Legislativo e Executivo nas decisões orçamentárias, que permitisse ao primeiro concentrar sua atenção nas decisões estratégicas sobre prioridades na alocação de recursos públicos, cuja responsabilidade deve caber aos políticos, e delegasse, ao segundo, a tarefa de implementar tais decisões. Como é o parlamento que forma o governo em regimes parlamentaristas, tal arranjo é mais fácil de ser estabelecido nesses casos, portanto, não é obra do acaso o orçamento de competência ter sido adotado inicialmente em países que adotam o regime parlamentarista de governo.

Nova Zelândia e Austrália, que lideraram as iniciativas de adotar o orçamento de competência, o fizeram no bojo de uma ampla reforma fiscal, que agregou, às demandas da macroeconomia por responsabilidade fiscal, a adoção de um novo regime orçamentário. Nessas reformas, os órgãos públicos que cuidam da gestão das políticas e programas governamentais ganharam autonomia para gerir os recursos a elas atribuídos em troca de compromissos com o alcance de metas de resultados, que são oficialmente estabelecidas e contratadas. Esse modelo estimula a competição entre as entidades públicas e tem como referência procedimentos de gestão semelhantes aos adotados pela iniciativa privada, que pode, inclusive, assumir a gestão de serviços públicos mediante um mandato específico. 
As reformas empreendidas nesses países foram objeto de detalhado escrutínio de organismos multilaterais e de governos de distintos países, tendo servido de referência para outras iniciativas semelhantes. Como não poderia deixar de ser, o Reino Unido enveredou pela mesma seara em seguida, em resposta a pressões do parlamento por maior controle sobre decisões orçamentárias estratégicas e da sociedade por uma melhor performance das organizações públicas encarregadas de gerenciar os gastos. No modelo britânico, todavia, algumas limitações foram acrescidas ao exercício da autonomia das agências governamentais para corrigir problemas identificados nas experiências precedentes, conforme será adiante comentado.

Entre os pioneiros, a preocupação com os riscos fiscais de longo prazo predominou na decisão de adotar a contabilidade de competência na Islândia, tendo em vista a necessidade que esse país enfrentava à época para conter a expansão dos gastos de pessoal. Preocupações semelhantes foram externadas em praticamente todos os casos em que esse regime contábil foi adotado, visto que a capacidade de antever riscos futuros de decisões adotadas no presente é uma de suas características importantes. Essa mesma questão tem predominado nos Estados Unidos, onde as preocupações com respeito à situação das contas públicas no longo prazo aumentaram recentemente em decorrência das medidas adotadas para combater a crise econômica, o que exige esforços continuados para aperfeiçoar a avaliação dos riscos fiscais decorrentes de obrigações assumidas pelo governo com a assistência médica a idosos e pessoas de baixa renda, além de outros programas de seguro social. ${ }^{1}$

A importância da contabilidade de competência para a avaliação de riscos fiscais é um aspecto que merece ser destacado. A questão aqui se refere às metodologias adotadas para avaliar ativos e passivos governamentais, especialmente os financeiros, cujas previsões dependem de hipóteses sobre o comportamento da economia, das taxas de juros e de desconto aplicadas e de estimativas de inflação, o que, dadas as incertezas inerentes a essas previsões, especialmente em uma economia cada vez mais globalizada, requer que os resultados sejam encarados com a devida cautela e submetidos a auditorias independentes para aumentar sua credibilidade. Não obstante, como há riscos fiscais decorrentes de programas de seguro social que são específicos de go-

\footnotetext{
${ }^{1}$ Após ter feito detalhados estudos sobre as experiências dos países que optaram por adotar o orçamento de competência, o governo norte-americano descartou essa opção por julgar que ela não atende à necessidade de melhor avaliar os riscos fiscais do país.
} 
vernos, é necessário desenvolver procedimentos específicos para avaliar esses riscos como vem sendo enfatizado por estudos feitos nos Estados Unidos.

No grupo dos pioneiros na implantação da contabilidade de competência no setor público, Holanda e Canadá se voltaram principalmente para os aspectos relacionados à eficiência do Estado e à melhoria da qualidade da gestão pública. Na Holanda, a adoção da contabilidade de competência foi parte de um amplo processo de reformas que tinha por objetivo rever o papel do Estado na economia e impulsionar um processo de privatização de parte das atividades então exercidas por organismos estatais e de devolução a governos locais de maior responsabilidade na provisão de serviços por meio da descentralização fiscal. Tomando como exemplo os Estados Unidos, os dois países também decidiram não adotar o orçamento de competência e utilizar as informações geradas pela contabilidade de competência para subsidiar decisões sobre o uso de recursos orçamentários nos casos em que isso é importante.

Uma adesão mais recente à adoção da contabilidade de competência no setor público foi a da França, que implementou essa mudança em 2006. No caso francês, a qualidade e a confiabilidade das informações sobre as contas públicas - tendo em vista o controle interno e externo do Estado - tiveram um peso importante na decisão de adotar esse regime. Daí a importância que foi dada a um diálogo permanente dos órgãos encarregados da auditoria interna com os encarregados da certificação. Nesse país, a certificação é vista como necessária para reforçar o controle do parlamento sobre as atividades do governo e aumentar a segurança dos parlamentares.

As mesmas motivações que ensejaram a adoção de reformas voltadas para a melhoria da performance do setor público, nos países mencionados, provocaram acalorado debate e muitos estudos na Suécia e na Dinamarca. Nesses dois países, que estiveram no grupo dos pioneiros na implantação da contabilidade de competência, discutiu-se intensamente a possibilidade de também se usar as informações geradas pela contabilidade de competência para modificar todo o processo de elaboração e execução do orçamento, seguindo a linha da Austrália e da Nova Zelândia. Após uma longa discussão, a Suécia descartou a proposta de adotar o orçamento de competência, e a Dinamarca optou por fazê-lo a partir de 2007. O Canadá, que também esteve entre os pioneiros na implantação da contabilidade de competência, vem postergando a implementação de propostas para adotar o orçamento de competência. 


\title{
Quadro 3
}

\section{Adoção de sistemas de custos em diferentes países: motivações}

\begin{abstract}
Sistemas de custos adotados como parte de uma ampla reforma voltada para o aumento da eficiência na gestão pública mediante introdução de competição na provisão de serviços e adoção de métodos privados de gestão

- Austrália, Nova Zelândia e Reino Unido são os países em que essa motivação predominou. Nesse caso, a adoção da contabilidade de competência é vista como uma etapa no caminho do orçamento de competência.

Avaliação de riscos fiscais de longo prazo

- Adoção da contabilidade de competência é importante para gerar informações que permitam avaliar riscos fiscais de longo prazo. Na Islândia, essa foi a principal motivação para adotar esse regime e conter a expansão dos gastos previdenciários. Essa também é uma preocupação importante nos Estados Unidos, principalmente agora com a adoção de medidas para combater a crise econômica.

Eficiência do Estado e melhoria da qualidade do gasto

- Holanda e Canadá, que estiveram entre os pioneiros na adoção da contabilidade de competência, deram mais ênfase à contribuição da contabilidade de competência para a eficiência do Estado e à adoção de reformas voltadas para a privatização e a devolução de maiores responsabilidades na provisão de serviços a governos locais, mediante a descentralização fiscal.

Qualidade, transparência e confiabilidade das informações sobre as contas públicas

- Essa foi uma motivação importante na França, que privilegiou a contribuição da contabilidade de competência para o controle interno e externo do Estado.
\end{abstract}

A transparência das informações geradas pela contabilidade de competência, decorrente da aplicação de padrões contábeis conhecidos e da chancela de auditorias independentes, é outro atributo importante para que esse regime contábil seja adotado pelo setor público. Disso depende a abertura de maiores possibilidades para os cidadãos exercerem controle sobre os gestores públicos e cobrarem a responsabilidade que eles têm de fazer melhor uso desses recursos.

Em todas as experiências internacionais aqui referidas, é unânime o reconhecimento da importância da adoção da contabilidade de competência no setor público, como base de um sistema de informações indispensável para a adoção de providências voltadas a melhorar a qualidade do gasto público, o que é corroborado por especialistas na matéria. No entanto, o debate internacional a respeito do tema é controverso no que se refere à importância e à necessidade de adotar também o orçamento de competência. A tendência atual parece ser a de adotar a contabilidade de competência como um sistema de informações de grande utilidade para a melhoria da qualidade das decisões sobre o uso e a gestão dos recursos públicos e não como a etapa de um processo que deve levar a modificações profundas na elaboração e na gestão do orçamento. 


\title{
Quadro 4 \\ Uso das informações geradas pela contabilidade de competência
}

\begin{abstract}
1- Como um sistema de informações que permite avaliar os custos do governo e fornecer elementos úteis para orientar as decisões orçamentárias, mediante a comparação dos custos incorridos na execução de programas e atividades com os respectivos resultados obtidos, bem como para avaliar os riscos fiscais de longo prazo.

Essa é a opção adotada por cinco dos dez países que adotaram a contabilidade de competência no âmbito do setor público: Canadá, Estados Unidos, França, Israel e Suécia. O Canadá tem uma proposta de evoluir na direção de adotar o orçamento de competência, mas França, Suécia e Estados Unidos não pensam em fazer o mesmo.

2- Como uma etapa que precede a adoção do orçamento de competência

Além dos pioneiros - Austrália, Nova Zelândia e Reino Unido - , a Suíça e a Dinamarca seguiram essa opção com uma importante diferença. Os três primeiros o fizeram logo em seguida à mudança no regime contábil, enquanto a Suíça e a Dinamarca só vieram a adotar o orçamento de competência em 2007.
\end{abstract}

Essa tendência se manifesta nos números. Dez países adotam a contabilidade de competência, ${ }^{2}$ mas apenas cinco entre eles optaram pelo orçamento de competência. ${ }^{3}$ Além disso, os que adoram o orçamento por competência posteriormente introduziram modificações para lidar com os principais problemas decorrentes dessa opção e um dos pioneiros, a Austrália, segundo um dos estudiosos desse tema, estaria cogitando retroceder e manter a contabilidade de competência como um sistema importante para a qualidade do gasto público.

É importante notar que o grupo de países que avançaram na implementação da contabilidade de competência no setor público é, hoje, mais heterogêneo do que o pequeno número de pioneiros. Além de regimes parlamentaristas formados na tradição de Westminster e outros de escolas distintas, a lista inclui regimes presidencialistas (Estados Unidos e Suíça), federações e países unitários com histórias, culturas e tradições distintas, o que indica não haver um traço comum que conduza à decisão de adotar, ou não, o regime em questão, ou explique o resultado obtido com tais experiências.

A despeito de sua importância, a adoção da contabilidade de competência no setor público não é uma tarefa trivial, pois significa modificar procedimentos e hábitos há muito arraigados. Idealmente, ela deve ser parte de um processo de reformas que inclui outras medidas importantes para consolidar a

\footnotetext{
${ }^{2}$ A lista inclui Austrália, Canadá, Dinamarca, Estados Unidos, França, Israel, Nova Zelândia, Reino Unido, Suécia e Suíça.

${ }^{3}$ Austrália, Dinamarca, Nova Zelândia, Reino Unido e Suíça.
} 
disciplina fiscal e aumentar a eficiência da gestão pública, a exemplo de regras fiscais e de mudanças organizacionais que apontem para o mesmo objetivo. Em todos os casos aqui referidos, a adoção da contabilidade de competência resultou de um longo e amplo debate sobre a importância de aumentar a eficiência do Estado, melhorar a qualidade do gasto e propiciar uma maior responsabilização dos governantes públicos. Nos casos da Austrália e da Nova Zelândia essa mudança foi promovida simultaneamente a um processo maior de reformas fiscais, em outros casos, sua adoção tem estimulado o avanço de outras reformas, cujos efeitos geram uma sinergia positiva e ampliam os resultados esperados. No Brasil, o debate em curso sobre a necessidade de aumentar a eficiência da gestão pública e melhorar a qualidade do gasto irá se beneficiar da iniciativa de adotar a contabilidade de competência no setor público, pois sem ela é impossível conhecer o real custo do governo e, portanto, tomar as medidas necessárias para reduzir desperdícios e adotar providências para obter melhores resultados na aplicação dos recursos públicos.

O reconhecimento dos desafios envolvidos na adoção da contabilidade de competência reforça a necessidade de um cuidadoso processo de preparação a fim de que as vantagens decorrentes das informações por ele geradas venham a ser plenamente aproveitadas. Nessa preparação é importante destacar o seguinte:

v a existência de pessoal habilitado a lidar com as complexidades inerentes à adoção de um regime contábil de competência;

v a implementação de mudanças que definam com clareza as responsabilidades de cada organização com respeito ao uso dos recursos públicos;

v a promoção de mudanças comportamentais, que concorram para firmar o compromisso com a qualidade do gasto na gestão pública;

v a geração de informações financeiras e não financeiras de boa qualidade, e de infraestrutura tecnológica com capacidade para processá-las, bem como a existência de entidades autônomas encarregadas da certificação dessas informações e de sua credibilidade perante a população;

- a divulgação, em forma clara e acessível, de análises das decisões sobre as prioridades no uso dos recursos públicos e sobre os resultados alcançados, de modo a criar condições efetivas de responsabilização de gestores e governantes;

- a realização de avaliações periódicas para promover as adaptações e ajustamentos necessários. 
Dessa lista, a capacitação dos servidores púbicos e a mudança de hábitos e comportamentos são requisitos essenciais. O foco nos aspectos macroeconômicos da gestão fiscal, que predominou em alguns países e tem sido particularmente acentuado no Brasil, concentrou os esforços de capacitação da máquina pública nos órgãos centrais encarregados da gestão financeira. Isso tem acarretado o enfraquecimento da capacidade dos organismos setoriais que respondem pela execução das políticas governamentais, tanto para elaborar programas e projetos quanto para gerenciar a sua implementação. Dada a importância que os órgãos setoriais desempenham para que os objetivos da adoção da contabilidade de competência sejam plenamente alcançados, é importante que os programas de capacitação estejam voltados para dotá-los da habilitação necessária para tanto.

Quanto aos esforços de um redesenho institucional, cabe considerar mudanças em estruturas e controles que adicionem princípios de conduta a serem observados por dirigentes e gestores e prevejam as devidas sanções. Essa foi, aliás, a opção adotada pelo modelo australiano, que instituiu um código de conduta (Estatuto de Honestidade Orçamentária de 1998) e os procedimentos para aferir a conformidade com as regras nele estabelecidas.

Para que a adoção da contabilidade de competência leve aos resultados que dela se espera, importa atentar, ainda, para os dois outros requisitos acima apontados: a existência de organismos autônomos para certificar a conformidade acima mencionada e a disponibilidade de informações transparentes que permitam aos cidadãos zelar pelo atendimento de seus interesses, inclusive mediante pressão para aplicação das sanções previstas quando deslizes forem claramente identificados.

\section{A adoção da contabilidade de competência deve levar necessariamente à adoção também de um orçamento de competência?}

Como mencionamos, a proposta de considerar a adoção da contabilidade de competência como uma etapa na direção da posterior adoção do orçamento de competência é controversa e, inclusive, estaria sendo abandonada por um dos países pioneiros. As razões para isso são apresentadas adiante.

Uma importante limitação à adoção do orçamento de competência tem a ver com os investimentos. Na proposta do orçamento de competência, as apropriações de recursos passam a ser feitas com base nos custos de produção de um bem ou da prestação de um serviço. Assim, no caso dos investimentos, 
as propostas orçamentárias elaboradas pelos diferentes órgãos encarregados dessas ações tomam por base o desgaste que o capital preexistente, ou o capital acrescido, sofreu em um determinado período para gerar os produtos ou prestar os serviços, isto é, o valor da sua depreciação nesse mesmo período. Os recursos recebidos à conta da depreciação de capital devem ser acumulados para financiar a sua reposição, quando necessário.

Uma vez aprovadas pelo Legislativo, essas propostas asseguram a cada órgão acesso automático aos recursos e total liberdade na sua gestão. Na sua versão pura, portanto, a proposta do orçamento de competência implica perda de controle dos órgãos centrais sobre a liberação dos recursos financeiros. Por isso, os países que optaram por adotar o orçamento de competência introduziram mudanças posteriores para garantir o controle sobre as liberações financeiras.

O conflito entre autonomia e controle central é um dos principais focos de resistência à proposta de adoção do orçamento de competência. De um lado, a concessão de autonomia aos responsáveis pela gestão das agências encarregadas da implementação das políticas públicas é considerada fundamental para que os objetivos dessa proposta, que repousa na criação de um ambiente competitivo e na adoção de métodos de gestão similares aos aplicados no setor privado, para promover a eficiência do gasto e a responsabilização dos gestores, sejam plenamente alcançados. De outro, o exercício dessa autonomia pode criar problemas para o controle sobre a execução financeira do orçamento, com potenciais problemas para o resultado fiscal no curto prazo.

Os problemas mencionados resultam do fato de que no orçamento de competência, os recursos postos à disposição das agências funcionam como uma conta especial, que contém não apenas os recursos necessários para financiar os gastos a serem efetivamente feitos no período, mas também as despesas que não implicam desembolso imediato, como previsões e depreciações. A rigor, portanto, na ausência de controle financeiro, nada impede que os saques contra essa "conta" excedam as previsões de necessidades de caixa do exercício, o que, caso envolvam recursos volumosos, são fonte de problemas. Ademais, a liberdade para vender ativos excedentes pode ser outra fonte de expansão dos gastos.

As implicações da proposta de adoção do orçamento de competência (accrual budgeting) para o manejo da política fiscal macroeconômica foram analisadas em profundidade (Robinson, 2009). O autor analisa se as informações geradas por esse regime orçamentário são suficientes ou podem ser ajustadas para atender aos objetivos de assegurar a disciplina e a sustentabilidade fiscal e promover a estabilidade macroeconômica.

O ponto de partida de sua análise consiste em deixar claro que a adoção do orçamento de competência implica que o controle das despesas passe a ser 
feito com base nas regras contábeis próprias desse regime. Assim, os limites quantitativos estabelecidos para as despesas de cada ministério, no caso em que um orçamento de competência é adotado, incluiriam:

- contas a pagar - montantes devidos em razão de bens e serviços entregues e utilizados durante o exercício financeiro, ainda que os pagamentos só venham a ocorrer no ano seguinte;

- os novos direitos previdenciários de servidores públicos adquiridos e acumulados durante o exercício financeiro;

v estoques (de suprimentos, por exemplo) efetivamente utilizados no processo de produção dos bens e serviços, sem considerar a data em que foram comprados;

v direitos de servidores públicos relativos a férias ou licenças remuneradas, adquiridos durante o exercício financeiro, ainda que eles só venham a ser utilizados posteriormente;

$\checkmark$ a depreciação dos ativos fixos.

Como é evidente, os valores das despesas totais de cada ministério, que resultariam da aplicação desse modelo, não se confundem com os valores gerados pelo regime de caixa. Daí a necessidade de examinar se, e como, as informações geradas em um regime orçamentário de competência atendem às exigências da política fiscal.

Com respeito à disciplina e à sustentabilidade fiscal, é importante dispor de informações que permitam ao governo conter a dívida pública, mediante controle sobre as despesas e o déficit. Nesse caso, Robinson (2009) menciona que um orçamento de competência não gera informações adequadas para o controle do déficit e, portanto, para a sustentação da disciplina e da sustentabilidade fiscal. Isso porque, ao incluir apenas a depreciação, nada é informado sobre a totalidade das despesas de capital que, portanto, não ficariam sujeitas a escrutínio e a restrições à sua expansão. Como os valores de despesas de capital tendem a ser expressivos, seu impacto na demanda agregada seria relevante, gerando déficits incontroláveis.

Para contornar essa limitação, a Nova Zelândia e o Reino Unido impuseram controles orçamentários adicionais sobre as despesas de capital, o que não ocorreu na Austrália e na Dinamarca. Não obstante, nestes dois últimos casos foram implantados controles discricionários sobre o total de investimentos que requerem aprovação do governo central, se o montante superar US\$ 10 milhões (Dinamarca), ou demandam (Austrália) que os 
planos de investimento de cada ministério sejam aprovados pelo Ministério da Fazenda como parte do processo de aprovação do orçamento. Em todos esses casos, portanto, o controle sobre as despesas de capital passa a ser feito pelo Poder Executivo e não pelo Parlamento durante a votação do orçamento.

A mesma limitação não se aplicaria, segundo o autor, ao controle da dívida, que poderia ser feito sem a necessidade de adotar limites baseados em conceitos de contabilidade de caixa, e de forma ainda mais adequada. Para isso, seria necessário tomar como referência o conceito de dívida financeira líquida (net financial debit) definido como a diferença entre passivos e ativos financeiros, informação gerada pela contabilidade de competência. Para fins de avaliar a sustentabilidade fiscal, esse conceito seria mais apropriado do que o gerado pelo regime de caixa, pois inclui, além das obrigações convencionais, os passivos previdenciários, as obrigações assumidas em contratos de leasing e em parcerias público-privadas, e o estoque de contas a pagar. Além de reconhecer outros elementos do passivo, o conceito adiciona ativos financeiros não usualmente considerados, como contas a receber, e, no caso de os resultados fiscais do governo central não incluírem empresas estatais, o valor da participação do governo no capital dessas empresas.

Em termos de fluxos, a contrapartida da dívida financeira líquida é a demanda de financiamento líquida, ${ }^{4}$ que, refletindo o conceito de dívida usado na contabilidade de competência, reconhece a necessidade de financiamento de transações que geram riscos fiscais sem afetar a medição da dívida líquida na forma tradicional, como é o caso do aumento no passivo previdenciário. De outra parte, exclui recursos provenientes da privatização, que não são consideradas receitas e sim transações financeiras. Esse agregado fiscal gerado pela contabilidade de competência é o utilizado pela União Europeia para fins de verificação de conformidade com o Pacto de Estabilidade e Crescimento. Segundo Robinson (2009), uma das possíveis razões para que essa medida não seja usada em um número maior de casos é que ela gera números mais elevados para a dívida e, portanto, maiores resistências políticas.

Convém notar que os resultados fiscais gerados por regimes contábeis distintos podem servir a diferentes propósitos. Se o interesse é controlar o

\footnotetext{
${ }^{4}$ Tradução livre de net lending/borrowing, da contabilidade de competência.
} 
resultado fiscal no curto prazo, o regime de caixa fornece indicações mais relevantes. Se, por outro lado, a preocupação é conhecer as implicações fiscais de médio e longo prazos o resultado gerado pelo regime de competência é o mais útil. A rigor, as duas medições são necessárias e complementam um sistema de informações que busca sustentar uma política de responsabilidade fiscal. O quadro 5 reúne algumas razões para diferenças geradas pelas duas medidas.

\section{Quadro 5 \\ Razões para as diferenças entre os resultados fiscais gerados pelos regimes de caixa e de competência}

- Despesas que reduzem os passivos previdenciários do governo: a exemplo de programas de demissões voluntárias e da privatização da previdência estatal. Essas despesas não alteram o resultado gerado pelo regime de competência se as despesas equivalem ao valor atuarial desses passivos, mas provocam uma acentuada deterioração do resultado fiscal obtido pelo regime de caixa.

- Mudanças importantes nos prazos de apuração e recolhimento de impostos: se o regime aplicado a um importante imposto é alterado de forma que, ao invés de o recolhimento ocorrer no exercício seguinte ao do fato gerador, ele passaria a ser feito no mesmo exercício, o resultado de caixa aumentaria no ano t e diminuiria no ano $t+1$, ao passo que o resultado de competência não seria alterado.

- Um incremento significativo na utilização de leasings financeiros ou de parcerias público-privadas para repor despesas de capital convencionais: isso melhoraria o resultado de caixa, mas afetaria o resultado de competência apenas na medida em que o custo de financiamento dessas alternativas diferisse do custo de fazê-lo diretamente.

- Recursos de privatização e de ingressos extraordinários de dividendos de empresas estatais: tais recursos geram impactos significativos no resultado de caixa sem alterar o resultado de competência.

Fonte: Robinson (2009).

Medidas usualmente adotadas no setor privado para medir a saúde financeira das empresas - o patrimônio líquido (net worth) e o balanço operacional líquido - não seriam recomendadas, pois o patrimônio líquido contempla também os ativos não financeiros que, no caso do governo, inclui estradas, prédios públicos e outros itens cujos valores não são facilmente atribuídos e, mesmo quando o são, não podem ser igualmente vendidos. De outra parte, o estabelecimento de metas para o déficit público com base no balanço operacional líquido não estaria impondo restrições a despesas de capital. ${ }^{5}$

\footnotetext{
${ }^{5}$ Robinson (2009) menciona que a utilização dessas medidas não geraria maiores problemas caso os governos adotassem a chamada regra de ouro, pela qual dívidas só deveriam ser contraídas
} 
Baseado nessas e em outras considerações, Robinson (2009) conclui que, embora um orçamento de competência seja compatível com uma boa política fiscal, na prática existem riscos decorrentes da complexidade desse regime orçamentário que demandariam um sistema de gestão financeira dotado de plenas condições para exercer um eficaz controle sobre os agregados fiscais gerados por esse regime. Tal consideração reforça a tese de que a adoção da contabilidade de competência no setor público é importante para gerar informações que contribuam para melhorar a qualidade das decisões orçamentárias e do gasto público, mas que a eventual transição de um orçamento de caixa para um orçamento de competência deve ser precedida de uma cuidadosa avaliação das suas implicações.

Além das questões relacionadas ao controle dos resultados fiscais, a proposta do orçamento de competência depende de que sua adoção seja precedida de uma rigorosa avaliação do estoque de capital preexistente, para que as estimativas de depreciação sejam confiáveis. Ademais, como um determinado estoque de capital pode ter usos diversos e sofrer desgastes que variam conforme a natureza do uso, a apropriação da parcela desse capital consumida na produção de um determinado bem ou serviço gera uma complicação adicional.

Mesmo a estimativa da depreciação do capital acrescido no período, em decorrência de novos investimentos, não é uma tarefa simples, pois requer conhecimento do prazo de vida útil de máquinas, equipamentos e instalações, bem como do processo de desgaste acumulado a cada ano, o que é necessário para definir o método adequado de depreciação. Ademais, mesmo que as estimativas sejam precisas, o desenvolvimento tecnológico aumenta o custo de reposição do capital depreciado, o que pode fazer com que as reservas acumuladas com base na depreciação do capital não sejam suficientes para financiar essa reposição quando ela for necessária.

Críticos da adoção de um orçamento de competência chamam a atenção, ainda, para dois outros problemas que podem advir dessa opção: o incentivo para que diferentes organismos governamentais subestimem o valor das depreciações, pois isto reduziria artificialmente o custo de obtenção do produto ou de provisão do serviço, dando uma indicação incorreta com respeito à eficiência dessas organizações; e como as demandas de recursos para investimentos encaminhadas ao Legislativo pelos órgãos setoriais referem-se

para financiar investimentos que gerassem benefícios futuros para a geração presente e cujos encargos sejam inteiramente assumidos no período de vida útil desses investimentos (o princípio da equidade intergerações). 
apenas aos valores da depreciação anual do capital, este não tem conhecimento do volume de recursos que será necessário em anos vindouros, o que diminuiria o poder de intervenção dos políticos em decisões importantes para o futuro do país.

Outra restrição à proposta do orçamento de competência aponta para a maior dificuldade de políticos e cidadãos compreenderem o sentido exato de informações obtidas com base em procedimentos contábeis mais sofisticados, o que poderia induzir a erros. Daí a recomendação dos principais especialistas em orçamento de utilizar a contabilidade de competência como um sistema adicional de informações, mantendo o regime de caixa para fins de elaboração e execução do orçamento.

A questão do controle político das decisões sobre o uso dos recursos públicos, especialmente aquelas que envolvem investimentos de grande monta relacionados a projetos estratégicos para o país, é uma das principais críticas que analistas norte-americanos fazem à adoção de um orçamento de competência. Entendem eles que, nesse caso, as autorizações de gasto seriam adotadas em um nível muito agregado e baseadas em informações complexas, o que dificultaria o entendimento, ainda que elas sejam acompanhadas de explicações que tenham em mira facilitar a compreensão. Dadas as características do regime presidencialista norte-americano, no qual o Congresso não abre mão de suas prerrogativas de controlar tais decisões, a adoção do orçamento de competência não é antevista. Esse problema não assume maior relevância em regimes parlamentaristas, nos quais o Executivo é formado pelo parlamento, que pode dissolver o governo em caso de grandes divergências a respeito de prioridades orçamentárias.

A diferença com que o tema é apreciado em regimes parlamentaristas se faz notar no Canadá, onde apesar das mencionadas dificuldades para o exercício do controle político no caso de ser adotado um orçamento de competência, o parlamento canadense vem se batendo pela plena adoção desse modelo orçamentário naquele país. Após analisar essa questão em detalhes, uma comissão especial do parlamento canadense, criada para tratar dessa matéria, concluiu por recomendar que o governo daquele país adote o orçamento de competência.

Para lidar com a principal questão relacionada ao ponto acima abordado — o controle sobre as decisões de investimento —, a comissão do parlamento canadense recomenda que na votação da proposta orçamentária o parlamento vote duplamente, tanto nos valores globais relativos ao montante dos investimentos, quanto nos valores previstos para as futuras despesas de amortização, o que também contribuiria para o avanço no sentido de apropriações plurianuais de recursos. Dessa forma, os valores necessários para cobrir custos ele- 
vados com a manutenção da infraestrutura econômica, por exemplo, ficariam devidamente assegurados.

Com respeito a outro ponto destacado pelos defensores da proposta de adoção do orçamento de competência — sua contribuição para o conhecimento do impacto futuro de decisões que estão sendo adotadas -, o problema está na diferença entre o poder público e a iniciativa privada no tocante a fatores que podem interferir nos resultados. Por exemplo, críticos da adoção do orçamento de competência mencionam que o maior patrimônio do governo é o poder que ele tem de tributar, e que boa parte dos ativos controlados pelo governo não podem ser avaliados com base em critérios adotados pelo setor privado, além de não serem passíveis de negociação ainda que essa avaliação fosse feita (recursos naturais e alguns itens da infraestrutura, por exemplo). De outra parte, uma parcela importante dos passivos governamentais, representada por seguros sociais que não fazem parte de regimes previdenciários tradicionais, como as garantias de prestação de serviços de saúde, por exemplo, não são contabilizados, em virtude de essa questão não ser reconhecida pelas normas contábeis aplicadas ao setor privado, como foi observado nos estudos norte-americanos antes mencionados.

\section{0 debate atual: da informação à decisão}

Como vimos, nos países que adotaram o orçamento de competência, tal mudança foi parte de um processo mais amplo de reformas institucionais associadas aos objetivos de revisão do papel do Estado na economia e de busca de maior eficiência e eficácia das políticas a cargo de distintas organizações governamentais mediante a adoção de mecanismos de gestão afins aos praticados pela iniciativa privada. Nos casos em que tal motivação não era predominante, entretanto, a decisão de transitar de uma contabilidade de competência para um orçamento de competência foi postergada, ou definitivamente abandonada.

Este é o caso da Suécia, um dos países pioneiros na aplicação da contabilidade de competência ao setor público, adotada pelo governo central em 1993, seguindo o que já vinha sendo praticado no nível dos governos locais e regionais desde meadas dos anos 1980. O argumento utilizado pelos defensores dessa mudança é que ela complementaria as informações sobre desempenho das agências governamentais que foram introduzidas no final dos anos 1980, de forma a permitir relacionar custos a desempenho.

A transição para o orçamento por competência na Suécia foi defendida no início da primeira década deste século, mas preocupações relacionadas 
com eventuais dificuldades de compreensão de informações de competência para fins de decisões orçamentárias, e com a possibilidade de descontrole das contas fiscais, fizeram com que a adesão a essa proposta fosse abandonada em 2004. Foi mantida então, a regra vigente há mais de uma década, de gerar informações contábeis segundo o regime de competência, mas preservar o regime de caixa nas decisões orçamentárias, o que veio a ser denominado de "abordagem dual". Nesse caso, as informações geradas pelo regime de competência são usadas para avalizar a performance das agências, mas não para apropriar os recursos do orçamento.

Esta questão está no centro dos debates atuais sobre o tema deste artigo: a adoção da contabilidade de competência no setor público deve ser vista como mais uma ferramenta para avaliar o desempenho do governo e contribuir para a melhoria das decisões sobre o uso dos recursos públicos, ou deve ser uma etapa na direção da adoção de um orçamento de competência?

Em favor da primeira opção, argumenta-se que as informações geradas pela contabilidade de competência são importantes para a avaliação do desempenho das organizações públicas, o que não ocorre com a contabilidade de caixa. Outro argumento menciona que essa opção fornece informações mais ricas sobre as finanças governamentais, que concorrem para melhorias na tomada de decisões. De outra parte, os defensores da segunda opção argumentam que as informações geradas pela contabilidade de competência serão de pouca utilidade para o orçamento se este mantiver o regime de caixa, pois os políticos não se interessarão por elas.

Vantagens e desvantagens dessas duas opções foram apreciadas em detalhe por Schick (2007), cujas principais observações a respeito são resumidas adiante.

A avaliação de riscos fiscais de governos é um dos aspectos que têm contribuído para críticas com respeito à insuficiência das informações geradas pelo regime de caixa, o que tem levado o International Public Sector Accounting Standards Board (Ipsab) a promover a adoção da contabilidade de competência no setor público, apoiado em regras fiscais internacionais que propiciam a auditoria financeira dos relatórios publicados por organismos governamentais. Em paralelo, algumas organizações internacionais estão cooperando para a adoção de um regime modificado de competência no sistema de contas nacionais. A adoção de regras fiscais de inspiração macroeconômica é outro fator que contribui para críticas ao regime de caixa para avaliar o desempenho fiscal do governo, uma vez que a possibilidade de manipulação do tempo em que as transações ocorrem, ou são reconhecidas, pode apontar para uma situação mais favorável do que a real. Apesar dessas críticas, Schick (2007) menciona que o orçamento de caixa tem a vantagem de ser mais com- 
preendido por governos e cidadãos e gerar indicadores melhores para avaliar a situação fiscal do governo no curto prazo.

\author{
Quadro 6
}

\title{
Principais restrições à adoção do orçamento de competência
}

\begin{abstract}
1. Despesas de capital - apropriadas com base no custo da depreciação e não na despesa total, com a realização de uma obra ou a aquisição de um equipamento. Tal fato gera reação dos políticos, que perdem controle sobre o montante total dos investimentos a ser executado em um dado período, visto que as informações encaminhadas ao Legislativo para votação do orçamento anual não conteriam essa informação.

2. Controle sobre a liberação dos recursos orçamentários - uma vez aprovadas as verbas atribuídas a cada órgão, estes passam a ter autonomia para utilizar os recursos a ele destinados, o que implica perda de controle dos órgãos centrais sobre a liberação dos recursos financeiros, com potencial de geração de riscos fiscais no curto prazo.

3. Inclusão de valores que não implicam desembolsos imediatos - os limites orçamentários de cada órgão incluiriam, por exemplo, os direitos dos servidores públicos adquiridos e acumulados durante o exercício financeiro - férias e previdência -, que só implicam desembolsos futuros, o que, na ausência de controles adicionais sobre a liberação financeira, agravaria o problema.

4. Dificuldade para o controle social - a complexidade das informações geradas pela contabilidade de competência pode dificultar a transparência dos valores incluídos no orçamento e, portanto, criar maiores barreiras ao controle da sociedade sobre as decisões orçamentárias em face de uma maior dificuldade de entendimento.

5. Limitações à avaliação de riscos fiscais de longo prazo - como um dos principais passivos governamentais refere-se a seguros sociais que não fazem parte de regimes tradicionais de previdência, a exemplo da saúde e da assistência social, em virtude de essa não ser uma questão pertinente no caso de empresas privadas, a proposta do orçamento de competência não gera informações suficientes a esse respeito.
\end{abstract}

De outra parte, o orçamento de competência tem a reputação de ser menos vulnerável a manipulações quando comparado ao regime de caixa. No orçamento de competência, o governo não melhora o resultado vendendo ativos, adiantando o recolhimento de impostos ou postergando pagamentos. Mas os resultados irão refletir a influência de metodologias e hipóteses adotadas no cálculo, a exemplo de taxas de juros e de desconto, bem como de critérios para reavaliar ativos, o que torna mais complexa a tarefa de identificar possíveis deslizes de conduta. Adicionalmente, o orçamento de competência é defendido com base na necessidade de o país dispor de conhecimento sobre a situação fiscal do governo no médio e longo prazos, e no fato de que sua adoção é importante para aumentar a eficiência do setor público e criar condições propícias à responsabilização de gestores e governantes. 
A curta experiência acumulada nessa área sugere, segundo o mesmo autor, que a opção de adotar a contabilidade de competência no setor público não implica necessariamente transitar para a adoção de um orçamento de competência. Nesse caso, o sistema de custos seria mais um componente de um conjunto de informações necessárias para a qualidade da gestão pública. Isto é, o sistema de custos seria uma ferramenta de grande utilidade para melhorar a qualidade do orçamento, mas as decisões de alocação dos recursos orçamentários e as regras aplicadas à execução do orçamento não adotariam os mesmos procedimentos.

\section{Quadro 7 \\ Orçamento de caixa e orçamento de competência: vantagens e desvantagens}

1. Orçamento baseado em informações de fluxos de caixa informa receitas e despesas sem considerar o momento em que ocorreram as atividades que geraram as receitas, os recursos foram consumidos, ou aumentaram as obrigações. O orçamento de competência considera as obrigações assumidas, independentemente de quando recebimentos e pagamentos são feitos ou recursos são consumidos, buscando alinhar o orçamento com o período em que recursos são consumidos ou passivos aumentados, ao invés do período em que obrigações são assumidas ou que os fluxos de caixa ocorrem.

2. As áreas em que ocorrem grandes diferenças na aplicação de um ou outro método são: pessoal civil e militar, meio ambiente, seguro social e ativos reais e financeiros. $\mathrm{O}$ orçamento de competência inclui benefícios previdenciários futuros de servidores públicos ativos nos custos de prestação de serviços, mas não inclui pagamento de inativos. Aquisição de equipamentos e obras de construção são contabilizadas integralmente no orçamento tradicional, mas apenas a depreciação é considerada no orçamento de competência.

3. Vantagens do orçamento de caixa: melhor compreendido por governos e cidadãos, menos inclinado a manipulações e produz melhores indicadores da situação fiscal do governo no curto prazo. Desvantagens do orçamento de caixa: governo pode melhorar a situação fiscal vendendo ativos, adiando pagamentos e antecipando impostos. Vice-versa, o orçamento de competência pode melhorar a situação fiscal manipulando hipóteses e métodos aplicados à valoração de ativos, ao recebimento de créditos duvidosos (dívida tributária ativa, ações de estatais...)

4. Desvantagens do orçamento de competência: transfere poder para os técnicos. Não gera informações suficientes para avaliar riscos fiscais de longo prazo, demandando estudos específicos a esse respeito. Subestima o custo dos investimentos (apenas a parcela da depreciação é contabilizada) e também custos operacionais (incentivo para não reconhecer a depreciação).

5. Orçamento de caixa não permite avaliar os custos de programas e projetos. Orçamento de competência enfrenta dificuldades para avaliar com precisão ativos e passivos (metodologias e premissas) e não substitui o orçamento de caixa. Por exemplo, limites ao endividamento são baseados em resultados de caixa.

Fontes: United States General Accounting Office (2007:7-8); Shick (2007:134-135). 
Por outro lado, embora curta, a experiência com o orçamento de competência tem levado os países pioneiros nessa iniciativa a promover ajustes que buscam contornar as suas principais deficiências, a exemplo dos ajustes promovidos no Reino Unido, Austrália e Nova Zelândia. Tais experiências também levaram os países que evoluíram posteriormente nessa direção a não estender o orçamento de competência ao campo dos investimentos, caso da Suíça, onde a adoção dessa opção gera maiores problemas.

De acordo com o diretor adjunto da Divisão de Orçamento e Despesas Públicas da OCDE, Jón Blöndal, o entusiasmo inicial com o orçamento de competência está arrefecendo e um dos países pioneiros na adoção desse regime orçamentário - a Austrália - o estaria abandonando. Segundo Blöndal, um dos fatores que pesou na decisão dos pioneiros de adotar o orçamento de competência foi a respeitabilidade de que goza a classe dos contadores na Austrália, Nova Zelândia e Reino Unido. Mas, a dificuldade que os políticos têm de entender as informações geradas pela contabilidade de competência contribuiu para reduzir o entusiasmo com a proposta de aplicar esse regime contábil ao processo de elaboração e gestão do orçamento. Além do recuo da Austrália, França e Áustria fizeram exaustivos estudos recentes a respeito e optaram pelo regime dual.

Na França, a implantação da contabilidade de competência foi concluída em 2006, quatro anos após a aprovação da lei que determinou a sua adoção no setor público. A ênfase dada à confiabilidade das informações nesse país se traduz na responsabilidade atribuída à confiabilidade das informações para fins do controle interno e externo sobre o Estado, mas o regime de competência não se estende ao processo orçamentário.

A tendência atual seria, portanto, a de enfatizar a importância da adoção da contabilidade de competência no setor público, mas manter o regime de caixa no que diz respeito à alocação dos recursos orçamentários.

\section{A experiência internacional e as diretrizes para adoção de um sistema de custos no setor público brasileiro}

De acordo com as diretrizes adotadas pelo Ministério da Fazenda, o sistema de informações de custos para o governo federal, que vem sendo construído desde 2008, tem o propósito de gerar dados que permitam avaliar:

$\checkmark$ a eficiência no uso dos recursos;

v a eficácia dos gestores na obtenção de suas metas; 
V a efetividade das políticas públicas na resolução dos problemas apresentados pela sociedade.

Para tanto, ele é visto como parte de um sistema mais amplo de informações que visam subsidiar as decisões de alocação de recursos, fornecer elementos importantes para a melhoria da gestão pública e propiciar a comparação dos resultados das ações governamentais com os custos incorridos na sua implementação.

Nessa linha, a proposta estabelece que as informações de custo integram-se conceitual e sistematicamente aos subsistemas de orçamento público, contabilidade governamental e processamento de dados, para compor um sistema de informações contábeis gerenciais do ente público a ser construído com base em dados e informações internas. Estabelece, ainda, que as informações de custo serão obtidas mediante reclassificações e ajustes nos dados de receitas e despesas gerados pela contabilidade governamental, de tal modo que os custos serão apropriados por categorias do sistema orçamentário (programática, funcional e institucional) e por produtos e serviços prestados, que estejam identificados e mensurados no sistema orçamentário. A acumulação dos custos de projetos e atividades, de acordo com a hierarquia do sistema contábil orçamentário, permitiria, então, obter o custo dos programas. Assim, o orçamento propiciaria o insumo para a obtenção dos custos e os custos forneceriam o insumo para a melhoria da qualidade do orçamento.

Da forma como é apresentada, depreende-se que a proposta de construção do sistema de custos passa a ser uma ferramenta importante para avançar na linha das reformas da gestão pública que vêm sendo adotadas ultimamente em várias partes do mundo. Nessa perspectiva, as decisões sobre o uso dos recursos públicos teriam por referência a relação entre os resultados obtidos na gestão desses recursos e os custos incorridos na sua obtenção. Com base nessa informação, contribuintes e cidadãos disporiam do conhecimento necessário para cobrar dos políticos, governantes e gestores públicos um compromisso firme com a geração de melhores resultados, a menores custos, e responsabilizá-los pela ocorrência de desperdícios. Mais valor pelo seu dinheiro é o lema que impulsiona essas reformas.

Na busca desse objetivo, a experiência internacional indica que há dois principais caminhos que podem ser percorridos. Um conduz à adoção do chamado orçamento de competência (accrual budgeting), mediante o qual o regime contábil de competência é a base para a apropriação de recursos e também para a execução do orçamento. Outro, chamado de regime dual defende a 
introdução da contabilidade de competência no setor público como elemento adicional de grande importância para a melhoria da qualidade das decisões orçamentárias, mas preserva o regime de caixa no processo de elaboração e gestão do orçamento.

Qualquer que seja a opção que venha a ser adotada no caso brasileiro, a experiência internacional abordada neste artigo recomenda que algumas questões sejam consideradas na implementação de um sistema de custos e sua integração ao processo orçamentário:

$\checkmark$ a importância que deve ser atribuída à qualidade, transparência e credibilidade do sistema de informações de custos e de medição do desempenho dos programas governamentais;

- a necessidade de manter, em paralelo, as informações geradas pelo regime de caixa sobre os principais agregados fiscais;

v a importância de preservar o controle financeiro sobre a execução do orçamento;

v a necessidade de acompanhar a implementação das mudanças, de modo a identificar possíveis problemas e promover as adaptações e ajustes que se fizerem necessários;

- a importância de dispor de auditorias independentes para certificar os relatórios da situação financeira do governo e de suas principais agências;

v a necessidade de investir os recursos necessários na capacitação das organizações e dos recursos humanos necessários para o bom resultado dessa iniciativa.

Todas essas questões foram consideradas críticas para o sucesso ou falhas ocorridas durante a implementação das reformas realizadas na Austrália e no Reino Unido, em um estudo conduzido cinco anos após a adoção do regime de competência nesses países, ${ }^{6}$ tendo a identificação das falhas levado à adoção de ajustes para superar os problemas daí advindos. O quadro 8 resume o resultado dessa análise.

Com os cuidados que estão cercando os trabalhos de preparação que têm por objeto a implementação de um sistema de custos no Brasil, a contínua observação dos ajustes e adaptações que vêm sendo empreendidos em vários países, tanto por parte dos que já avançaram nessa linha e estão trabalhando

\footnotetext{
${ }^{6}$ Scheers, Sterck e Bouckaert (2005).
} 
no seu aperfeiçoamento, quanto por parte dos que estão estudando o assunto e dando alguns passos iniciais, é recomendável para adicionar novos elementos úteis para o desenvolvimento da proposta brasileira.

\section{Quadro 8 \\ Fatores críticos para o sucesso ou falhas das reformas implementadas na Austrália e no Reino Unido}

\begin{tabular}{|lcc|}
\hline Fator & Austrália & Reino Unido \\
Conexão entre mudanças no ciclo orçamentário (políticas, gestão e & + & - \\
finanças) & & - \\
Transparência e qualidade dos dados & - & + \\
Atenção constante às informações de caixa & + & + \\
Cultura orçamentária orientada para resultados & + & - \\
Tecnologia da informação & - & + \\
Atribuição de responsabilidade aos gestores & + & + \\
Disponibilidade de recursos & + & + \\
Conhecimento especializado e know-how & - & + \\
Cooperação e suporte dos órgãos centrais & + & + \\
Avaliação e ajustamentos periódicos & + & + \\
Coordenação dos níveis de governo & + & + \\
\hline
\end{tabular}

Obs.: Sinal positivo $=$ sucesso; sinal negativo $=$ falhas.

\section{Síntese e conclusões}

Em síntese, um olhar sobre a experiência internacional, à luz das diretrizes traçadas para o projeto brasileiro, recomendaria dar atenção especial aos seguintes aspectos:

- as motivações - o que detonou o interesse em promover a mudança na contabilidade do setor público;

v as justificativas — quais as razões alegadas para a adoção da contabilidade de competência no setor público;

v a utilização - em que medida e com que finalidade as informações geradas pela contabilidade de competência são utilizadas; 
- as limitações - quais as principais dificuldades enfrentadas para a adoção desse regime no setor público;

- os cuidados - quais as medidas adotadas para lidar com alguns problemas relacionados ao uso das informações geradas pela contabilidade de competência.

Vale ressaltar que a experiência internacional registra uma forte relação entre as propostas de mudança na contabilidade do setor público e os movimentos de reforma da gestão pública que se intensificaram a partir dos anos 1980, sobretudo na linha denominada new public management, buscando maior eficiência mediante a promoção de um ambiente competitivo e a adoção de métodos de gestão afins aos praticados pelo setor privado.

Ademais, reformas voltadas para a gestão mais eficiente dos recursos públicos ganharam força no contexto de preocupações com a necessidade de conter o crescimento dos gastos públicos, pois só assim seria possível reduzir a carga tributária com vistas a preservar a competitividade econômica no mercado global.

Por seu turno, a promoção da eficiência no setor público depende de as autoridades disporem de informações confiáveis sobre o custo incorrido por distintos órgãos e departamentos na provisão dos serviços mantidos pelo Estado. Sem que se conheçam os custos, é impossível avaliar se os resultados obtidos em diferentes áreas de atuação das organizações governamentais poderiam ser substancialmente melhorados, ou se poderiam ser alcançados com um menor emprego de recursos humanos, materiais e financeiros.

A ênfase na eficiência com que os recursos extraídos compulsoriamente dos cidadãos são aplicados transforma-se, portanto, na principal justificativa para a mudança no regime contábil. O lema "mais valor para o seu dinheiro" busca enfatizar a importância de o contribuinte se sentir respeitado no tocante ao uso que o governo faz dos recursos públicos.

O foco no desempenho vem acompanhado do aumento da transparência. Mediante a divulgação de como os recursos orçamentários são aplicados, quais as prioridades a eles conferidas, quanto custa a prestação de um determinado serviço e quais os benefícios que ele traz para a sociedade, as autoridades públicas estariam contribuindo para o reforço dos ideais democráticos. Isto se dá mediante a criação de melhores condições para que o cidadão possa exercer maior controle sobre as atividades do Estado e cobrar, de seus representantes no Parlamento, as medidas necessárias para corrigir eventuais desvios e desperdícios.

Motivações e justificativas não diferem significativamente nas distintas experiências de adoção da contabilidade de competência no setor público. O 
que difere é o uso que é feito das informações geradas por esse regime. A principal diferença se refere ao fato de o regime de competência ser visto como uma ferramenta adicional de grande importância para a tomada de decisões sobre o uso dos recursos públicos, ou se esse mesmo regime leva a mudanças radicais no orçamento, caso em que tanto as decisões de alocação de recursos quanto a execução orçamentária adotam o regime de competência.

Entre esses dois casos extremos estão algumas variações que buscam adotar as informações geradas pela contabilidade de competência para decisões orçamentárias em casos específicos, como a previdência oficial de servidores públicos, ou preservar o regime de caixa para decisões relativas à realização de investimentos.

Nessa mesma linha, cabe ressaltar a importância que a aplicação da contabilidade de competência desempenha para a avaliação de riscos fiscais de longo prazo e, portanto, para o manejo de uma política fiscal voltada para a sustentação da disciplina fiscal. A esse respeito duas áreas são focos importantes de preocupação: as implicações de decisões relativas ao funcionalismo, que geram compromissos futuros não imediatamente reconhecidos pelo regime de caixa; e o recurso ao endividamento para financiar gastos cujo retorno seja incapaz de gerar recursos suficientes para satisfazer os compromissos a serem atendidos.

Qualquer que seja o uso a ser feito das informações geradas pela contabilidade de competência, em todas as experiências abordadas neste artigo, as mudanças requeridas para adotar esse regime no setor público enfrentam limitações importantes que, se não forem devidamente consideradas, podem criar sérias dificuldades à implementação desse regime.

As principais limitações mencionadas referem-se à carência de pessoal especializado na administração pública em métodos e procedimentos próprios do setor privado. Daí a importância atribuída a um intenso programa de treinamento e capacitação como pré-requisito para o sucesso de qualquer iniciativa nessa direção.

A rigor, não é apenas um programa de capacitação técnica, mas sim uma mudança de hábitos e comportamentos que precisa ser promovida para que os benefícios de uma mudança na contabilidade pública sejam integralmente aproveitados.

A adaptação dos servidores públicos a um novo regime não é a única dificuldade enfrentada. As informações geradas pela contabilidade de competência são mais difíceis de ser compreendidas, tanto pela classe política quanto pela população, o que requer um grande esforço de comunicação que a transparência que se pretende com essa mudança seja de fato alcançada. 
$\mathrm{O}$ anterior sugere que alguns cuidados sejam tomados para que o projeto de adoção da contabilidade de competência no setor público gere os benefícios que dele se espera. Primeiro, é necessário que todos os setores da administração pública estejam convencidos da sua importância e comprometidos com o projeto. Segundo, é importante desenvolver, em paralelo ao esforço de implementação dessa reforma, um amplo programa de treinamento para os servidores de órgãos centrais e setoriais, voltado para a capacitação necessária a essa mudança. Terceiro, fazer com que as informações geradas pela contabilidade de competência sejam acompanhadas de demonstrativos que deem transparência a essa informação. Quarto, promover uma campanha de divulgação voltada para angariar o apoio dos políticos e da sociedade e, assim, garantir o contínuo aperfeiçoamento desse novo regime.

Como qualquer sistema de informações, os benefícios que serão dele extraídos dependem da confiabilidade das informações e de como elas são utilizadas. Com respeito à confiabilidade, as experiências indicam que além da transparência dos procedimentos utilizados na aferição dos custos, a certificação dos números por auditorias independentes é uma providência importante para os fins do projeto.

No tocante ao uso, os argumentos reunidos ao longo do artigo e o recuo que vem sendo observado em um dos países pioneiros na extensão do regime de competência ao processo orçamentário reforçam a tese de que o projeto brasileiro de construção de um sistema de informações voltado para a aferição dos custos do setor público brasileiro deveria contemplar a adoção de um regime dual, no qual as informações de custos contribuem para a melhoria das decisões sobre o uso dos recursos públicos, mas no qual a apropriação dos recursos orçamentários preserva o regime de caixa.

Enquanto as informações de custo geradas pela contabilidade de competência são fundamentais para a eficiência e eficácia da gestão pública, as informações de caixa são necessárias para manter o controle político sobre as decisões de investimento e a gestão macroeconômica das contas fiscais, evitando riscos de descontrole no curto prazo. De outra parte, as informações geradas pela contabilidade de competência são indispensáveis para avaliar riscos fiscais de longo prazo, em especial aqueles relacionados a regimes previdenciários dos servidores públicos, além de poder contribuir para o alargamento das decisões orçamentárias e a aplicação de uma política fiscal anticíclica. 
Um último ponto tem a ver com as particularidades de um regime federativo com respeito a mudanças voltadas para a eficiência do Estado e a melhoria da qualidade do gasto público. Na maioria das experiências de adoção de sistemas de custos, os governos locais precederam o governo central no que diz respeito à adoção da contabilidade de competência. No Brasil, a importância que estados e municípios desempenham na gestão do gasto público recomenda que a iniciativa que está sendo adotada pelo governo federal estimule a adoção de mudanças similares pelos governos subnacionais, tendo em vista evitar que metodologias distintas venham a comprometer futuramente a cooperação intergovernamental e o comprometimento de todos os entes federados com os objetivos do projeto.

\section{Referências}

BLÖNDAL, Jón R. Accrual accounting and budgeting: key issues and recent developments. OECD Journal on Budgeting, Paris, v. 3, n. 1, 2003.

. Issues in accrual budgeting. OECD Journal on Budgeting, Paris, v. 4, n. 1, 2004. 2008.

et al. Budgeting in Australia. OECD Journal on Budgeting, Paris, v. 8, n. 2, McCORMACK, Lee. Performance budgeting in Canada. OECD Journal on Budgeting, v. 7, n. 4, 2007.

McPHEE, Ian. Financial management in the public sector: how accrual accounting enhances governance and accountability. In: CPA AUSTRALIA PUBLIC SECTOR FINANCE AND MANAGEMENT CONFERENCE. Anais... Australian National Audit Office, Aug. 2006.

PAULSSON, Gert. Accrual accounting and cash budgeting - the prospects for running a dual system. Sweden: Department of Business Administration, School of Economics and Management, Lund University, 2007.

ROBINSON, Marc. Accrual budgeting and fiscal policy. Washington: IMF, 2009.

SCHICK, Allen. Performance budgeting and accrual budgeting: decision rules or analytic tools? OECD Journal on Budgeting, Paris, v. 7, n. 2, 2007. 
SCHEERS, Bram; STERCK, Miekatrien; BOUCKAERT, Geert. Lessons from Australian and British reforms in results-oriented financial management. OECD Journal on Budgeting, Paris, v. 5, n. 2, 2005.

UNITED STATES GENERAL ACCOUNTING OFFICE. Accrual budgeting. Experiences of other nations and implications for the United States. Washington: GAO, 2000. . Budget issues. Accrual budgeting useful in certain areas but does not provide sufficient information for reporting on our nation's longer - term fiscal challenge. Washington: GAO, 2007. 